\title{
Os olhares de futuros professores sobre a metodologia de trabalho de projeto
}

\section{Looks of future teachers on the methodology of project works}

\author{
Carlos Alberto Ferreira ${ }^{1}$
}

\begin{abstract}
RESUMO
Tendo feito a formação de futuros professores do $1^{\circ}$ ciclo do ensino básico na metodologia de trabalho de projeto, foi nossa intenção recolher as opiniões deles sobre a utilização dessa metodologia na educação escolar. Os resultados obtidos mostram que os futuros professores compreenderam o conceito e a prática da metodologia de trabalho de projeto, com opiniões próximas daqueles descritos teoricamente, referindo várias vantagens na sua utilização no processo de ensino e de aprendizagem. Por esta razão, são, também, da opinião que é importante a formação de professores nessa metodologia de ensino e de aprendizagem.
\end{abstract}

Palavras-chave: trabalho de projeto; formação de professores; opiniões de futuros professores.

\begin{abstract}
Having done the training of future teachers of the 1st cycle of basic education on the methodology of project works, it was our intention to gather their opinions on the use of this methodology in school education. The results show that future teachers understood the concept and practice of the methodology of project works, with opinions which are close to those described theoretically by referring several advantages in its use in teaching and learning. For this reason, they also assume the opinion that teacher training is important in that teaching and learning methodology.
\end{abstract}

Keywords: project works, training of teachers; opinions of future teachers.

${ }^{1}$ Doutor em Educação, na especialização em Desenvolvimento Curricular pela Universidade de Trás-os-Montes e Alto Douro. Professor na Universidade de Trás-os-Montes e Alto Douro. Investigador do Centro de Investigação em Educação da Universidade do Minho; Portugal. E-mail: caferreira@utad.pt. 


\section{Introdução}

No contexto da sociedade da informação e do conhecimento, é exigido às escolas e aos professores que ajudem os alunos a compreenderem, a integrarem e a mobilizarem a informação a que vão tendo acesso para as tarefas ou problemas com que se deparam na sua vida quotidiana, o que permite aos alunos atribuírem sentido e utilidade àquilo que aprendem.

Por estarmos convictos que só quando a educação escolar permite dar resposta às necessidades e aos interesses dos diferentes alunos é que tem relevância para eles, que nos propusemos, desde há alguns anos a esta parte, formar futuros professores do $1^{\circ}$ ciclo do ensino básico da Universidade de Trás-os-Montes e Alto Douro na metodologia de trabalho de projeto. Passado algum tempo de realização dessa formação, foi nosso intuito verificar as opiniões desses futuros professores sobre a utilização da metodologia de trabalho de projeto na educação escolar. Para isso, elaborámos e administrámos um questionário com cinco questões abertas àqueles que realizaram a formação nos anos letivos de 2010/11 e de 2011/12, que nos permitiu obter as informações procuradas e que aqui pretendemos apresentar e refletir.

Assim, começamos o presente artigo com a abordagem de algumas ideias teóricas sobre a formação de professores no contexto da sociedade da informação e a metodologia de trabalho de projeto. O ponto seguinte é iniciado com uma breve referência teórica sobre a prática da dita metodologia, passando, a seguir, para a descrição da formação feita dos futuros professores do $1^{\circ}$ ciclo do ensino básico da Universidade de Trás-os-Montes e Alto Douro na metodologia de trabalho de projeto. Depois, apresentamos o problema e os objetivos do estudo e caraterizamos os procedimentos metodológicos de recolha e de análise das opiniões sobre a utilização do trabalho de projeto na educação escolar. Por fim, apresentamos e refletimos sobre as referidas opiniões dos futuros professores do $1^{\circ}$ ciclo do ensino básico.

\section{A formação de professores no contexto da sociedade da informação e a metodologia de trabalho de projeto}

A sociedade atual caracteriza-se por haver um grande e rápido desenvolvimento científico e tecnológico, que leva a que esteja disponível cada vez mais informação sobre os fenómenos que nela ocorrem. Os alunos vão tendo 
acesso a esta informação de uma forma rápida e fácil por outras vias para além da escola, nomeadamente através da televisão e da internet. Dada a quantidade e a diversidade de informações disponíveis e dada a importância e a valorização do conhecimento para a vida em sociedade e para o exercício de uma profissão, Hargreaves (2003) e Pacheco (2011) denominam a sociedade atual de sociedade do conhecimento e da informação.

Esta realidade vem, por um lado, perspetivar e exigir a educação ao longo da vida (DELORS et al., 1996), numa lógica de permanente atualização de conhecimentos e do desenvolvimento de competências necessárias à adaptação às circunstâncias mutantes da vida em sociedade, e, por outro lado, vem redimensionar o papel da escola e dos professores na educação escolar. Passa a ser-lhes exigido que criem efetivas condições pedagógicas que permitam aos alunos gerirem, compreenderem, integrarem e utilizarem a informação a que vão tendo acesso, para poderem responder aos problemas e aos desafios com que se vão defrontando na sua vida numa sociedade da informação e do conhecimento (FERREIRA, 2010; MAINGAIN; DUFOUR, 2008). Daí que não seja suficiente que a educação escolar instrua os alunos num conjunto de saberes teóricos, por vezes desligados da sua vida e aos quais não atribuem significado. A ela é exigido que crie oportunidades para que os alunos construam aprendizagens de conhecimentos e adquiram competências diversas (MAINGAIN; DUFOUR, 2008). Isto é, a escola e os professores são chamados a conceberem situações de ensino e de aprendizagem de saberes úteis, do saber-fazer, saber-ser, saber viver juntos e com os outros (DELORS et al., 1996). Para além disso, têm que estimular a capacidade dos alunos na mobilização, de forma integrada, desses diferentes saberes e competências, de modo a poderem responder às exigências da sua vida pessoal, social e, posteriormente, profissional. Entende-se, aqui, a competência como "uma capacidade que revela o domínio de um conjunto de saberes, reportado a um dado corpus de conhecimento, e que se pode tornar visível num dado contexto de acção" (PACHECO, 2011, p. 44).

É preciso, por isso, redimensionar o papel e as caraterísticas da educação escolar, consequentemente, a formação de professores. E isto porque cabe aos professores ajudarem os alunos a encontrarem, a compreenderem, a integrarem e a utilizarem a informação a que vão tendo acesso para a resposta às diversas solicitações que vão tendo no seu dia a dia (MAINGAIN; DUFOUR, 2008). Neste sentido, Charlot e Silva (2010, p. 55) afirmam que hoje a formação de professores deve orientar-se pela ideia de que é

cada vez mais indispensável o professor do saber, ou seja, aquele docente que consegue ensinar como procurar e ligar informações para produzir 
sentido, para entender o mundo, a vida, as nossas relações com os demais e conosco mesmos.

Por outro lado, resultante do fenómeno da massificação, a população escolar passou a caraterizar-se por nela existirem alunos com caraterísticas, necessidades e interesses muito distintos. Por esta razão, o professor tem que ser formado para ser capaz de dar resposta à diversidade de alunos e às exigências sociais, estruturando o ensino com situações pedagógicas que permitam aos alunos construírem a aprendizagem, gerindo o currículo escolar de forma flexível, em função das necessidades e dos interesses dos seus alunos, e apostando na utilização de estratégias pedagógicas diferenciadas que conduzam a uma igual mestria do maior número possível deles (SOUSA, 2010).

Neste contexto, o ensino e a aprendizagem por projetos que resultam dos interesses e das necessidades dos diferentes alunos afigura-se como um método de ensino e de aprendizagem (KILPATRICK, 2006) que pode constituir uma resposta pedagógica àqueles desígnios (FERREIRA, 2008; PERRENOUD, 2000; 2001).

Também os imperativos colocados pela sociedade atual à educação escolar e aos professores pressupõem que a formação do professor lhe possibilite conhecimentos e a capacidade reflexiva, investigativa e criativa sobre as suas práticas pedagógicas (ALONSO, 2005; MARCELO, 2009). Para isso, é necessário que lhes proporcione os instrumentos teóricos, técnicos e práticos indispensáveis, desenvolvendo nos professores competências curriculares e pedagógico-didáticas, competências de investigação e de reflexão (ALONSO, 2005). Mas, também é imprescindível o desenvolvimento de competências pessoais e relacionais, já que é com o trabalho colaborativo que os professores mais facilmente encontram as respostas para os diferentes desafios com que se deparam no quotidiano escolar (ALONSO, 2005; MORGADO, 2005). Por outro lado, a formação de professores tem que ser entendida como uma formação ao longo da vida profissional, não devendo os professores encararem a formação inicial como suficiente para darem resposta a todos os desafios profissionais que vão encontrar ao longo da sua a vida. Neste sentido, refere Marcelo $(2009$, p. 8) que

ser professor no século XXI pressupõe o assumir que o conhecimento e os alunos (as matérias-primas com que trabalham) se transformam a uma velocidade maior à que estávamos habituados e que, para se continuar a dar uma resposta adequada ao direito de aprender dos alunos, teremos de fazer um esforço redobrado para continuar a aprender. 
As constantes mudanças a que se assiste na sociedade, na economia, na política levam a que a educação escolar e, consequentemente, a ação dos professores, tenham que ser constantemente redimensionadas, por forma a conseguirem dar resposta às exigências que lhe são feitas, garantirem a qualidade pedagógica e o maior sucesso escolar possível nos seus alunos, conseguido através de um processo contínuo de formação e de desenvolvimento profissional do docente.

\section{O trabalho de projeto na formação de professores do $1^{\circ}$ ciclo do ensino básico da Universidade de Trás-os-Montes e Alto Douro}

Tendo em consideração o contexto social em que vivemos e as exigências feitas à formação de professores, parece-nos que a formação na metodologia de trabalho de projeto pode constituir uma das respostas pedagógicas possíveis e adequadas. Isto porque o trabalho de projeto estrutura-se por projetos que resultam de problemas dos interesses dos alunos e/ou sociais, normalmente manifestados por questões ou por curiosidades por eles sentidas, que são elaborados e desenvolvidos pelos alunos, sob a orientação do professor (FERREIRA, 2008; LEITE; MALPIQUE; SANTOS, 2001). Na procura de respostas para esses problemas, os alunos, agrupados em função de interesses comuns, pesquisam informações das várias áreas do saber em diferentes fontes e mobilizam-nas, de forma integrada (BEANE, 2002; FERREIRA, 2010), para a elaboração de produtos que registam as respostas encontradas. Deste modo, pode dizer-se que através da aprendizagem por projetos são desenvolvidas competências fundamentais nos alunos para o seu sucesso educativo e para a vida ativa na sociedade atual, tais como a cooperação, a tomada de decisões, a seleção e a análise de informações em função de objetivos determinados, a autonomia, a responsabilidade e o aprender a aprender (CRUZ, 2010; CRUZ; FERREIRA, 2010).

Por sua vez, a organização do processo de ensino e de aprendizagem por projetos implica que os futuros professores façam uma gestão flexível dos conteúdos programáticos das diferentes áreas curriculares e/ou disciplinas, em função dos projetos delimitados (FERREIRA, 2010). Pressupõe o exercício de funções de observação e de orientação dos grupos de alunos no decorrer dos projetos, numa perspetiva de avaliação formativa contínua dos processos de trabalho e de aprendizagem deles. Daí que associada à implementação desta metodologia está a necessidade da utilização de medidas de diferenciação curricular e pedagógica, uma vez que os projetos dos alunos são diferentes, bem como as necessidades que durante a realização das atividades vão evidenciando. 
Toda esta prática implica uma postura de negociação, de reflexão e, também, criativa da parte dos futuros professores ao longo do processo de ensino e de aprendizagem.

Dadas as vantagens formativas do trabalho de projeto para os alunos e para os futuros professores, temos vindo a formar futuros professores do $1^{\circ}$ ciclo do ensino básico da Universidade de Trás-os-Montes e Alto Douro nessa metodologia de ensino e de aprendizagem. Esta formação tem vindo a ser realizada no âmbito de uma disciplina semestral, inicialmente do plano de estudos da Licenciatura em Educação Básica e, de há quatro anos para cá, com a implementação do Processo de Bolonha, do Mestrado em Educação Pré-Escolar e Ensino no $1^{\circ}$ Ciclo do Ensino Básico. Esta formação tem-se concretizado com uma componente teórica e outra prática (FERREIRA, 2008). A componente teórica é realizada numa hora semanal em sala de aula na universidade e destina-se à clarificação dos conceitos de projeto, de projeto pedagógico e dos pressupostos do trabalho de projeto. Também nesta componente teórica são discutidas propostas de diferentes autores para a implementação dessa metodologia, o papel do professor e do aluno na mesma. Ainda se destina à reflexão e à orientação dos diferentes grupos de futuros professores no trabalho a realizar na parte prática da disciplina. A componente prática é concretizada pelos futuros professores em turmas do $1^{\circ}$ ciclo do ensino básico, para onde se deslocam num dia por semana, organizados em grupos de três elementos. Nela, começam por diagnosticar os interesses dos alunos, a partir dos quais são formados grupos de alunos do $1^{\circ}$ ciclo do ensino básico em função de interesses comuns e se delimitam os problemas que vão originar os projetos a serem elaborados e desenvolvidos durante o semestre, com a orientação dos futuros professores. Estando definidos os projetos, com as questões formuladas e com o plano de atividades que cada grupo de alunos realizou com a orientação dos futuros professores, os alunos iniciam as pesquisas em diferentes fontes (por exemplo, em livros, em revistas, na internet, através de entrevistas, etc). Durante as pesquisas, os futuros professores verificam a qualidade da informação que os alunos estão a selecionar, se estão a compreender essa informação, ajudam-nos no esclarecimento de dúvidas ou de dificuldades e conduzem-nos a aprofundarem os aspetos necessários. Através do processo de pesquisa, vão sendo realizados produtos (por exemplo: textos, cartazes, powerpoints, artigos para o jornal escolar, álbuns, etc.), que registam as informações recolhidas e analisadas e com as quais respondem às questões levantadas inicialmente. Durante todo este processo, quer os futuros professores, quer os alunos, através da sua autoavaliação, vão avaliando se o plano de atividades está a ser cumprido, se estão a encontrar as respostas para 
as questões/problemas levantados e quais as aprendizagens que estão a fazer. Depois de concluído o projeto, os diferentes grupos preparam e apresentam o trabalho realizado aos colegas e, quase sempre, à comunidade escolar, onde se incluem os próprios pais (FERREIRA, 2008).

Desta forma, e considerando com Perrenoud (2000) que a utilização da metodologia de trabalho de projeto constitui uma resposta pedagógica importante para os desafios profissionais docentes, os futuros professores são formados em conhecimentos, técnicas e competências imprescindíveis ao exercício da docência.

\section{A metodologia de investigação utilizada no estudo}

Depois de vários anos de formação de futuros professores do $1^{\circ}$ ciclo do ensino básico na metodologia de trabalho de projeto na Universidade de Trás-os-Montes e Alto Douro (Portugal), foi nosso intuito auscultarmos e refletirmos sobre as opiniões desses futuros professores sobre a utilização da metodologia de trabalho de projeto na educação escolar dos alunos.

\section{A questão/problema e os objetivos do estudo}

A questão/problema que conduziu ao estudo foi a seguinte: quais as opiniões de futuros professores do $1^{\circ}$ ciclo do ensino básico da Universidade de Trás-os-Montes e Alto Douro sobre a utilização da metodologia de trabalho de projecto na educação escolar dos alunos?

Assim, com o estudo realizado procurámos cumprir os seguintes objetivos: conhecer as conceções sobre a metodologia de trabalho de projeto de futuros professores do $1^{\circ}$ ciclo do ensino básico da Universidade de Trás-os-Montes e Alto Douro que experienciaram uma formação nesse domínio; identificar os contextos didáticos apontados por eles para a utilização da metodologia de trabalho de projeto; compreender as vantagens e as desvantagens apontadas na utilização da referida metodologia de ensino e de aprendizagem; verificar a importância atribuída por eles à formação na metodologia de trabalho de projeto. 


\section{Procedimentos de recolha e de análise de dados}

Para darmos resposta à questão/problema e aos objetivos a que nos propusemos, construímos um questionário com cinco questões abertas (SOUSA, 2005), organizadas com a seguinte sequência: "1-o que é para si a metodologia de trabalho de projeto?; 2-qual a utilização que pode ser dada à metodologia de trabalho de projeto na educação escolar?; 3-Que vantagens atribui à utilização da metodologia de trabalho de projeto na educação escolar? 4-Quais as desvantagens que a utilização da metodologia de trabalho de projeto traz para a educação escolar? 5-Considera importante que a formação de professores contemple a metodologia de trabalho de projeto? Por quê?". Depois de elaborado este questionário, fizemos a validação de conteúdo do mesmo (FOX, 1987). Para isso, solicitamos a três futuros professores do $1^{\circ}$ ciclo do ensino básico que não fizeram parte da amostra, mas que tinham experienciado a mesma formação na metodologia de trabalho de projeto, que o analisassem e opinassem sobre a clareza das questões e sobre se as mesmas eram suficientes para obtermos as informações pretendidas. Estes três futuros professores consideraram as questões claras e adequadas aos objetivos que pretendíamos com a utilização do questionário. Por esta razão, não foi necessário proceder a alterações no mesmo. Foi, então, que administrámos o questionário a vinte e nove futuros professores do $1^{\circ}$ ciclo do ensino básico, do Mestrado em Educação Pré-Escolar e Ensino no $1^{\circ}$ Ciclo do Ensino Básico, que tinham feito a formação na metodologia de trabalho de projeto no âmbito de uma disciplina do primeiro semestre do ano letivo de 2010/11 e de 2011/12. Essa administração foi feita diretamente pelo docente que orientou a formação e ocorreu no início do segundo semestre dos mesmos anos letivos, no final de uma aula de outra disciplina do curso. O questionário era anónimo e foi-lhes garantida a confidencialidade das suas respostas, tal como é sugerido pelas recomendações éticas da investigação em educação (LIMA, 2006). Os futuros professores responderam a todas as questões, sem que tivesse havido necessidade de qualquer esclarecimento.

Depois de recolhidos os questionários, procedemos à análise de conteúdo das respostas dadas às questões, através de um processo de categorização emergente (BARDIN, 1995). Da análise de conteúdo realizada emergiram as seguintes categorias e subcategorias: 1-“conceito de trabalho de projeto"; 2-"contextos educativos de utilização do trabalho de projeto", com as seguintes subcategorias: "em todas as áreas curriculares/ programas" e "tratar temas dos interesses dos alunos"; 3-"papel do aluno"; 4-"vantagens do trabalho de projeto", com as seguintes subcategorias: "desenvolver competências nos alunos", "ensino 
interdisciplinar", "realização de aprendizagens significativas pelos alunos", "criar hábitos de pesquisa", "autonomia dos alunos", "estímulo ao trabalho cooperativo", "esclarecimento de dúvidas/ interesses dos alunos", "facilidade na aprendizagem dos conteúdos" e "maior interesse e participação dos alunos na aprendizagem"; 5-desvantagens do trabalho de projeto, com as seguintes subcategorias: "complexidade da metodologia", "dificuldade dos alunos no trabalho de grupo", "dificuldade em responder a todas as curiosidades dos alunos"; "dificuldade no acompanhamento dos diferentes temas" e "necessidade de muito tempo"; 6-"razões para a formação de professores", com as seguintes subcategorias: "abordagem ecológica do processo de ensino e de aprendizagem", "metodologia a adotar no futuro", "desenvolver hábitos de pesquisa nos alunos", "valorização da metodologia" e "melhor preparação para o ensino".

\section{A utilização da metodologia de trabalho de projeto vista pelos futuros professores do $1^{\circ}$ ciclo do ensino básico da Universidade de Trás-os- -Montes e Alto Douro}

Os resultados obtidos através do questionário serão seguidamente apresentados pelas categorias que emergiram da análise das respostas dos futuros professores do $1^{\circ}$ ciclo do ensino básico e discutidos em função das orientações teóricas estabelecidas.

\section{Conceito de trabalho de projeto}

A metodologia de trabalho de projeto foi proposta por Kilpatrick, em 1918, no seu artigo intitulado "The project method", com o intuito de constituir um método de ensino e de aprendizagem alternativo a um ensino abstrato e transmissivo, desligado dos interesses e das necessidades dos alunos (KILPATRICK, 2006). O autor defendia que o ensino deveria centrar-se e dar resposta a essas necessidades dos alunos, que constituíam a origem dos projetos. Para a satisfação dessas necessidades e interesses, os alunos planeavam e realizavam atividades de pesquisa em pequenos grupos, das quais resultavam produtos que sintetizavam as respostas encontradas (FERREIRA, 2008; LEITE; MALPIQUE; SANTOS, 2001). Entende-se, por isso, o projeto pedagógico como "um estudo aprofundado 
de um assunto ou problema que um grupo, mais ou menos alargado, de crianças leva a cabo a partir de um interesse forte dos seus elementos e baseado numa planificação conjunta do próprio grupo" (RANGEL, 2002, p. 12). Verifica-se, assim, que um projeto pedagógico articula intenções (questões dos alunos que evidenciam necessidades e interesses dos mesmos) com ações - atividades por eles realizadas para concretizar as intenções (CORTESÃO; LEITE; PACHECO, 2002), sendo a metodologia de ensino e de aprendizagem implementada como "uma forma de conceber, de organizar e de intervir no processo de ensino e de aprendizagem por projetos pedagógicos" (FERREIRA, 2008).

Esta conceção de metodologia de trabalho de projeto é partilhada por todos os futuros professores inquiridos, uma vez que a referiram como um método de ensino e de aprendizagem que parte dos interesses e das necessidades dos alunos. Estes manifestam-se por questões/ curiosidades sobre fenómenos do meio de que fazem parte e cujas respostas são obtidas pela concretização, em pequenos grupos com interesses comuns (CASTRO; RICARDO, 1993; MANY; GUIMARÃES, 2006), de um conjunto de etapas de trabalho. Após constituídas, as respostas obtidas, os resultados do projeto e as aprendizagens feitas pelos alunos são comunicadas aos colegas e/ou à comunidade escolar, pois como afirma Rangel (2002), os saberes construídos e as restantes aprendizagens feitas têm que ser partilhadas para benefício de todos. Esta conceção de trabalho de projeto pode ser verificada através de uma das respostas mais elucidativas dos futuros professores inquiridos:

\begin{abstract}
"Na metodologia de trabalho de projeto os alunos fazem perguntas sobre temas do seu interesse, depois escolhem como vão fazer a pesquisa e como vão organizar as informações e, por fim, como vão comunicá-las. É um método em que os alunos têm total responsabilidade pelas aprendizagens" (FUTURO PROFESSOR T).
\end{abstract}

Esta afirmação demonstra que os futuros professores do $1^{\circ}$ ciclo do ensino básico interiorizaram um conceito de trabalho de projeto como um método de ensino e de aprendizagem (KILPATRICK, 2006) que parte de um ou mais problemas dos alunos e para os quais são planeadas e realizadas atividades de pesquisa em diferentes fontes e elaborados produtos diversificados (FERREIRA, 2008; LEITE; MALPIQUE; SANTOS, 2001; RANGEL, 2002). Atividades estas que vão permitir encontrar as respostas para as questões que esses alunos colocaram e que delimitaram o(s) problema(s) de pesquisa. As aprendizagens feitas são, depois, comunicadas aos colegas e à comunidade escolar, no intuito 
da partilha dessas aprendizagens (CASTRO; RICARDO, 1993; FERREIRA, 2008; LEITE; MALPIQUE; SANTOS, 2001; MANY; GUIMARÃES, 2006).

\section{Contextos de utilização do trabalho de projeto}

Em Portugal, o trabalho de projeto foi lançado com o aparecimento de uma área curricular não disciplinar designada de "Área-escola", no contexto das reformas curriculares dos ensinos básico e secundário de finais da década de oitenta e inícios da de noventa do século XX. Com a reorganização curricular do ensino básico, implementada em 2001, e com a do ensino secundário, em 2004, a Área-escola passou a designar-se de "Área de Projeto" (PORTUGAL, 2001; 2004). Trata-se de uma área curricular não disciplinar que, não tendo um programa definido, se concretiza pela elaboração e pelo desenvolvimento de um projeto que resulta dos interesses dos alunos e para o qual todas as áreas curriculares disciplinares, ou disciplinas contribuem (RANGEL, 2002). Mas, independentemente da existência desta área curricular não disciplinar, era aconselhada, oficialmente, a utilização do trabalho de projeto nas várias áreas curriculares ou disciplinas, na medida em que consiste num método de ensino de aprendizagem que cria condições para os alunos construírem aprendizagens significativas dos conteúdos programáticos (MINISTÉRIO DA EDUCAÇÃO, 2001).

A experiência de formação dos futuros professores do $1^{\circ}$ ciclo do ensino básico na metodologia de trabalho de projeto não ocorreu, na maioria dos casos, com o desenvolvimento do projeto da Área de Projeto, mas com projetos que emergiram das questões dos alunos sobre fenómenos do meio natural ou social que pretendiam compreender. Daí que os futuros professores do $1^{\circ}$ ciclo do ensino básico tenham afirmado que essa metodologia pode ser utilizada para dar resposta às questões ou curiosidades dos alunos e para lecionar os programas de todas as áreas curriculares disciplinares que fazem parte do plano curricular do $1^{\circ}$ ciclo do ensino básico português, que são: Língua Portuguesa; Estudo do Meio; Matemática; Expressões (PORTUGAL, 2001), como se pode ver, por exemplo, na seguinte afirmação de um futuro professor:

"Pode ser utilizada em todas as áreas, logo que surja uma diversidade de questões a serem respondidas" (FUTURO PROFESSOR AE). 
Os futuros professores são da opinião que esses conteúdos programáticos são geridos flexivelmente em função das curiosidades ou questões dos alunos. Tal abordagem dos conteúdos através de projetos pedagógicos pressupõe a diferenciação e a integração curriculares, entendida, esta última, como a articulação de conceitos e de procedimentos de diversas ciências para a exploração de um tema ou problema (BEANE, 2002; FERREIRA, 2010), no intuito da abordagem sistémica ou complexa da realidade e dos fenómenos que a constituem (MAINGAIN; DUFOUR, 2008). Só com este tipo de abordagem dos programas das disciplinas é que a educação escolar se pode tornar mais significativa para os alunos e os prepara para a compreensão e para a integração ativa na sociedade do conhecimento e da informação em que vivem (HARGREAVES, 2003).

\section{O papel do aluno na metodologia de trabalho de projeto}

Na metodologia de trabalho de projeto são os próprios alunos os principais atores, uma vez que são eles que decidem o(s) problema(s) a pesquisar, planificam e realizam as atividades que lhes permitem encontrar as respostas para as suas questões, avaliam o desenvolvimento do projeto e as aprendizagens que estão a fazer e apresentam os resultados obtidos à comunidade escolar (CASTRO; RICARDO, 1993; CORTESÃO; LEITE; PACHECO, 2002; FERREIRA, 2008; LEITE; MALPIQUE; SANTOS, 2001). Por isso, aprendizagem resulta de um processo autónomo e responsável de negociação e de tomada de decisões dos alunos (BOUTINET, 1996). Estas ideias sobre o papel do aluno na metodologia de trabalho de projeto são partilhadas pelos futuros professores, como se pode verificar nas seguintes afirmações:

\footnotetext{
"Tem a particularidade de conferir aos alunos um papel mais ativo do que aquele que tradicionalmente lhes é atribuído" (FUTURO PROFESSOR N). "São os próprios alunos que dão início aos projetos de trabalho, com as suas curiosidades que têm. Com o trabalho de projeto respondem às suas questões" (FUTURO PROFESSOR X).
}

Dada a centralidade dos alunos na metodologia de ensino e de aprendizagem, o papel do professor é o de ajudar os alunos a estabelecerem consensos, de os orientar na seleção e na análise das informações que vão recolhendo nas 
diferentes fontes (DELGADO, 2011). Também têm o papel de avaliar o que os alunos vão aprendendo e as dificuldades que vão sentindo, no sentido de os ajudar a ultrapassá-las, ou de os levar a aprofundar as respostas encontradas. É através das pesquisas que os alunos fazem aprendizagens integradoras dos conteúdos e que desenvolvem competências, como a tomada de decisões, a cooperação, a autonomia, a responsabilidade, a autoavaliação, etc. (BEANE, 2002; CRUZ, 2010; LEITE; MALPIQUE; SANTOS, 2001).

\section{Vantagens do trabalho de projeto}

O trabalho de projeto é um método de ensino e de aprendizagem que apresenta muitas vantagens, na medida em que o ensino tem sentido a utilidade para os alunos (FERREIRA, 2010), permitindo-lhes adquirir conhecimentos e desenvolver competências úteis à continuação dos estudos e à sua vida na sociedade do conhecimento, que está em constante mudança (CRUZ, 2010; FERREIRA, 2010; HARGREAVES, 2003; PERRENOUD, 2001). Como nos diz Kilpatrick (2006, p. 15), com a metodologia de trabalho de projeto, a educação escolar faz "parte da própria vida e não uma mera preparação para a vida." É neste sentido que os futuros professores apontaram várias vantagens à sua utilização no processo de ensino e de aprendizagem. Referiram que possibilita criar hábitos de pesquisa nos alunos, desenvolver-lhes a autonomia e estimular-lhes o trabalho cooperativo, como se pode ver nas afirmações que se seguem:

\footnotetext{
"Aprendem sobre a dúvida que têm a partir da pesquisa. [...] Tem como vantagem partir das dúvidas e curiosidades dos alunos" (FUTURO PROFESSOR B).

"Cria hábitos de pesquisa" (FUTURO PROFESSOR M).

"Esta metodologia faz com que as crianças possam ser mais autónomas" (FUTURO PROFESSOR O).

"[Esta metodologia estimula] a participação de todos os alunos, o trabalho cooperativo" (FUTURO PROFESSOR P).
}

Também mencionaram como vantagem o maior interesse e motivação dos alunos na aprendizagem, porque, para além de procurarem respostas para as suas curiosidades/ questões, é-lhes dada maior liberdade na escolha do que aprender e como aprender: 


\begin{abstract}
"A troca de ideias e de informação motiva mais as crianças e faz com que elas aprendam melhor e que elas se sintam mais interessadas e envolvidas" (FUTURO PROFESSOR L).

"A principal vantagem da metodologia de trabalho de projeto é que parte dos interesses dos alunos, ou seja, é mais motivadora, uma vez que os alunos pesquisam sobre um tema que realmente querem desenvolver" (FUTURO PROFESSOR U).
\end{abstract}

Estando os alunos motivados para a aprendizagem, porque encontram nesse processo uma funcionalidade e um sentido (FERREIRA, 2010), alguns futuros professores afirmaram que os alunos realizam aprendizagens significativas e desenvolvem competências, na medida em que eles mobilizam diferentes saberes na procura das respostas para as suas questões (CRUZ, 2010; PERRENOUD, 2001), o que concretiza um ensino de natureza interdisciplinar (POMBO; GUIMARÃES; LEVY, 1994):

"[...] Estamos a contribuir para agilizar a capacidade de mobilizar saberes por parte dos alunos" (FUTURO PROFESSOR G).

"Contraria a tendência para fragmentar a lecionação das diversas áreas [do $1^{\circ}$ ciclo do ensino básico]” (FUTURO PROFESSOR R).

Entende-se o ensino de natureza interdisciplinar como "qualquer forma de ensino que estabeleça uma qualquer articulação entre duas ou mais disciplinas" (POMBO; GUIMARÃES; LEVY, 1994, p. 11). No caso concreto do trabalho de projeto orientado pelos futuros professores do $1^{\circ}$ ciclo do ensino básico, o ensino interdisciplinar era conseguido pelo facto de os alunos articularem conceitos e procedimentos das várias áreas curriculares desse nível de ensino para a resposta às questões que originaram o projeto.

\title{
Desvantagens da utilização da metodologia de trabalho de projeto
}

Se o trabalho de projeto assume vantagens relativamente às metodologias de ensino tradicionais e passivas para os alunos, também pode trazer algumas desvantagens que advêm da complexidade do método (ABRANTES, 2002), uma vez que é necessário gerir conteúdos diversificados em função das questões colocadas pelos 
alunos, gerir a orientação a dar aos diferentes grupos de trabalho (CRUZ, 2010) e ser capaz de dar respostas didáticas ao imprevisto e à diversidade de necessidades dos vários alunos. Para além disso, o ensino e a aprendizagem por projetos exige tempo (ABRANTES, 2002), o que nem sempre é compatível com a necessidade de cumprimento dos programas das várias áreas curriculares e disciplinas. Apesar de vários futuros professores não mencionarem qualquer desvantagem, alguns indicaram a complexidade da metodologia, dada a imprevisibilidade do processo de ensino e de aprendizagem e a necessidade de respostas pedagógico-didáticas diferenciadas, como se pode verificar, por exemplo, nesta afirmação:

"A complexidade desta metodologia faz com que esta não seja, por vezes, bem empregue" (FUTURO PROFESSOR C).

Exigindo o trabalho de projeto um papel do professor de observador, de orientador e de avaliador do trabalho dos alunos, alguns dos futuros professores mencionaram a dificuldade na resposta a todas as dúvidas e interesses dos alunos no acompanhamento dos diferentes projetos, como se pode ver na seguinte afirmação:

"Numa turma heterogénea, os interesses das crianças podem ser muito variados e, sendo assim, é difícil responder a todas as dúvidas e interesses” (FUTURO PROFESSOR B).

Talvez por os alunos das suas turmas não estarem habituados a trabalhar em pequenos grupos, alguns futuros professores referiram esta dificuldade como a maior desvantagem para a utilização da metodologia de trabalho de projeto, como se pode comprovar na seguinte afirmação:

"Esta metodologia só acarreta uma desvantagem, que é o trabalho de grupo, que, por vezes, quando as crianças não estão habituadas, não é fácil" (FUTURO PROFESSOR P).

O trabalho de grupo é uma estratégia implícita à aprendizagem por projetos. Para isso, os alunos têm que o ver "como um conjunto de pessoas que interagem 
têm consciência umas das outras e se percecionam como um grupo" (CASTRO; RICARDO, 1993, p. 21). Ou seja, têm que perceber que deve haver regras interiorizadas por todos, no sentido de se respeitarem, de todos contribuírem para a realização das tarefas que eles próprios assumiram e de se responsabilizarem quer pelo cumprimento dos objetivos a que se propuseram, quer pelo bom funcionamento do grupo (FREITAS, L. V.; FREITAS, C. V., 2003).

Porque um projeto é um trabalho que exige tempo, alguns futuros professores viram nesse tempo necessário e no trabalho que ele implica uma desvantagem da metodologia, como se pode constatar na seguinte afirmação:

"Demora muito tempo, mais trabalhoso e mais barulhento" (FUTURO PROFESSOR T).

Pois, o ensino e a aprendizagem por projetos é um processo complexo, de negociação e de consensos, marcado por imprevistos aos quais se tem que dar resposta, exigindo, por isso, um tempo relativamente longo (ABRANTES, 2002).

\section{Razões para a formação de professores na metodologia de trabalho de projeto}

Num contexto educativo onde impera a diversidade de interesses e de necessidades dos alunos, a educação escolar depara-se com novos desafios. É preciso que a educação escolar crie condições para que os alunos construam as aprendizagens (de saberes, de atitudes, de procedimentos) em função dessa diversidade de necessidades e de interesses, de forma a capacitá-los para (con) viverem num mundo em constante mudança (HARGREAVES, 2003). Deste modo, a formação dos professores no ensino por projetos pode, segundo Perrenoud (2000) constituir uma resposta pedagógica adequada aos desafios atuais.

As opiniões dos futuros professores sobre a importância da formação nessa metodologia de ensino foram positivamente consensuais, referindo várias razões para isso. Alguns deles disseram que a formação nessa metodologia os prepara melhor para o ensino com os desafios que lhes são colocados atualmente, que os alunos têm um papel mais ativo, os motiva mais e cria nele hábitos de pesquisa: 


\begin{abstract}
"Acho importante que nós, futuros professores, tenhamos formação na metodologia de trabalho de projeto, na medida em que contraria, em parte, o ensino tradicional, permitindo à criança ter um papel mais ativo nas atividades letivas" (FUTURO PROFESSOR A).

"Criar hábitos de pesquisa e mais participação nas atividades por parte dos alunos” (FUTURO PROFESSOR M).
\end{abstract}

Por todas estas razões apontadas pelos futuros professores, percebemos que consideram importante a formação na metodologia de trabalho de projeto, pelo que é uma experiência a continuar e a melhorar nos aspetos referidos como desvantajosos.

\title{
Considerações finais
}

O ensino e a aprendizagem por projetos são referidos como uma proposta pedagógica que facilita a realização de aprendizagens com sentido e úteis aos alunos numa sociedade do conhecimento e da informação como a que se vive atualmente (FERREIRA, 2010; PERRENOUD, 2000). Foi com esta certeza que decidimos, desde há uns anos para cá, formar futuros professores do $1^{\circ}$ ciclo do ensino básico na metodologia de trabalho de projeto. As opiniões dos futuros professores permitiram-nos perceber que entenderam o que é e como se pratica a metodologia de trabalho de projeto. Foram muito mais as vantagens do que as desvantagens apontadas para a utilização dessa metodologia. Referiram que o trabalho de projeto permite o desenvolvimento de competências importantes nos alunos, como a autonomia e a responsabilidade, a pesquisa e o saber trabalhar em pequenos grupos. Ainda afirmaram que possibilita um ensino de natureza interdisciplinar, resultante da articulação e mobilização de conteúdos de várias áreas do saber para a busca de respostas para as questões colocadas pelos alunos. Referiram, deste modo, que os alunos se sentem mais motivados para aprender e fazem aprendizagens com mais sentido e utilidade à sua vida em sociedade. Tendo em conta estas opiniões, não estranhamos nenhum futuro professor ter manifestado uma opinião contrária à da continuação da formação na metodologia de trabalho de projeto. Por isso, é nossa intenção continuar a formar futuros professores neste domínio, procurando que a mesma diminua as desvantagens mencionadas à implementação desta metodologia de ensino e de aprendizagem. É preciso que essa formação, construída pelos futuros professores em função 
das suas necessidades, os auxilie a gerir, com respostas pedagógicas adequadas, a diversidade de temas ou de questões que originam os projetos existentes numa turma e a diversidade de necessidades que os alunos vão evidenciando no desenvolvimento dos projetos. Que também os ajude a adquirirem e a implementarem técnicas eficazes para o trabalho de grupo dos alunos, a organizarem e a gerirem adequadamente o tempo necessário à procura de respostas para as questões colocadas e que originam os projetos. É, portanto, uma experiência de formação a continuar e a aperfeiçoar em função das necessidades dos futuros professores, nomeadamente nestas que foram referidas e noutras que se forem evidenciando naqueles que vierem a vivenciar a formação.

\section{REFERENCIAS}

ABRANTES, P. Trabalho de projecto na escola e no currículo. In: ABRANTES, P.; FIGUEIREDO, C.; VEIGA SIMÃO, A. M. Reorganização Curricular do Ensino Básico. Novas Áreas Curriculares. Lisboa: Ministério da Educação- Departamento da Educação Básica, 2002, p. 21-38.

ALONSO, L. Questões críticas acerca da construção de um currículo formativo integrado. In: PORTUGAL, G.; PEREIRA, L. A. (Org.). Actas do I Simpósio Nacional de Educação Básica: Pré-Escolar e Primeiro Ciclo. Formação de Professores e Educadores de Infância. Questões do Presente e Perspectivas Futuras. Aveiro: Universidade de Aveiro, 2005, p. 2-17 (Publicado em CD-ROM).

BARDIN, L. Análise de Conteúdo. Lisboa: Edições 70, 1995.

BEANE, J. Integração Curricular. Lisboa: Didáctica Editora, 2002.

BOUTINET, J.-P. Antropologia do Projecto. Lisboa: Instituto Piaget, 1996.

CASTRO, L. B.; RICARDO, M. M.. Gerir o Trabalho de Projecto: Guia para a Flexibilização e Revisão Curriculares. Lisboa: Texto Editora, 1993.

CHARLOT, B.; SILVA, V. A. De Abelardo até à classificação de Xangai: as universidades e a formação de docentes. Educar em Revista, Curitiba, n. 37, p. 39- 58, maio/ago. 2010.

CORTESÃO, L.; LEITE, C.; PACHECO, J. A. Trabalhar por Projectos em Educação. Uma inovação interessante? Porto: Porto Editora, 2002.

CRUZ, D. A Metodologia de Trabalho de Projecto e a Internet. Aprendizagens de alunos do $1^{\circ}$ Ciclo do Ensino Básico. Dissertação (Mestrado em Ciências da Educação)- Departamento de Educação e Psicologia, Universidade de Trás-os-Montes e Alto Douro. Vila Real, 2010. 
CRUZ, D.; FERREIRA, C. A. Aprendizagens de alunos na metodologia de trabalho de projecto com a utilização da internet. In: COSTA, F. A. et al. (Orgs.). Actas do I Encontro Internacional TIC e Educação. Lisboa: Instituto de Educação da Universidade de Lisboa, 2010, p. 203-210 (Publicado em CD-ROM).

DELGADO, P. S. Métodos, principios y estrategias didácticas. In: MAYO, I. C.; PINOJUSTE, M. (Coords.). Diseño y desarrollo del curriculum. Madrid: Alianza Editorial, 2011, p. 185-203.

DELORS, J. et al. Educação: um tesouro a descobrir. Relatório para a UNESCO da Comissão Internacional sobre Educação para o século XXI. Porto: Edições Asa, 1996.

FERREIRA, Carlos Alberto. Metodologia de Trabalho de Projecto na Formação de Professores do $1^{\circ}$ Ciclo do Ensino Básico. In: FERREIRA, J.; SIMÕES, A. R. (Org.). Complexidade: um novo paradigma para investigar e intervir em educação? Actas do XV Colóquio Afirse/ Secção Portuguesa. Lisboa: Faculdade de Psicologia e de Ciências da Educação da Universidade de Lisboa/ Afirse- Secção Portuguesa, 2008. (Publicado em CD-ROM).

FERREIRA, C. A. Vivências de Integração Curricular na Metodologia de Trabalho de Projecto. Revista Galego-Portuguesa de Psicoloxía e Educación, v. 18, n. 1, p. 91-105, 2010.

FOX, D. El proceso de investigación en educación. Pamplona: EUNSA, 1987.

FREITAS, L. V.; FREITAS, C. V. Aprendizagem Cooperativa. Porto: Edições Asa, 2003.

HARGREAVES, A. O Ensino na Sociedade do Conhecimento. A educação na era da insegurança. Porto: Porto Editora, 2003.

KILPATRICK, W. O Método de Projecto. Viseu: Edições Pedago, 2006.

LEITE, E.; MALPIQUE, M.; SANTOS, M. R. Trabalho de Projecto 1. Aprender por Projectos Centrados em Problemas. 4. ed. Porto: Edições Afrontamento, 2001.

LIMA, J. A. Ética na investigação. In: LIMA, J. A.; PACHECO, J. A. (Orgs). Fazer Investigação. Contributos para a elaboração de dissertações e teses. Porto: Porto Editora, 2006, p.127-159.

MAINGAIN, A.; DUFOUR, B. Abordagens Didácticas da Interdisciplinaridade. Lisboa: Instituto Piaget, 2008.

MANY, E.; GUIMARÃES, S. Como abordar a metodologia de trabalho de projeto. Lisboa: Areal Editores, 2006.

MARCELO, Carlos. Desenvolvimento Profissional Docente: passado e futuro. Sísifo/ Revista de Ciências da Educação, n. 8, p. 7-22, 2009.

MINISTÉRIO DA EDUCAÇÃO. Currículo Nacional - Competências Essenciais. Lisboa: Ministério da Educação - Departamento da Educação Básica, 2001. 
MORGADO, J. C. Mudança das Práticas Curriculares: Realidades e Perspectivas. In: MORGADO, J. C.; ALVES, M. P. (Orgs.). Mudanças educativas e curriculares ... e os Educadores/Professores? Braga: Centro de Investigação em Educação - Universidade do Minho, 2005. p. 265- 280.

PACHECO, J. A. Discursos e Lugares das Competências em Contextos de Educação e Formação. Porto: Porto Editora, 2011.

PERRENOUD, P. Dez Novas Competências para Ensinar. Porto Alegre: Artmed Editora, 2000 .

PERRENOUD, P. Porquê construir competências a partir da escola? Desenvolvimento da autonomia e luta contra as desigualdades. Porto: Edições Asa, 2001.

POMBO, O.; GUIMARÃES, H.; LEVY, T. A Interdisciplinaridade: Reflexão e Experiência. Lisboa: Texto Editora, 1994.

RANGEL, M. Áreas Curriculares Não Disciplinares. Porto: Porto Editora, 2002.

SOUSA, A. Investigação em Educação. Lisboa: Livros Horizonte, 2005.

SOUSA, F. Diferenciação Curricular e Deliberação Docente. Porto: Porto Editora, 2010.

\section{Legislação consultada}

PORTUGAL. Decreto-Lei n ${ }^{\circ}$ 6, de 18 de janeiro de 2001. Reorganização curricular do ensino básico português. Diário da República, jan. 2001.

PORTUGAL. Decreto-Lei n ${ }^{\circ}$ 74, de 26 de março de 2004. Reorganização curricular do ensino secundário português. Diário da República, mar. 2004.

Texto recebido em 17 de setembro de 2012.

Texto aprovado em 29 de maio de 2013. 